\title{
9. Top-down versus bottom-up pathways to collaboration between governments and citizens: reflecting on different participation traps
}

\author{
Ingmar van Meerkerk
}

\section{INTRODUCTION}

Collaboration in policymaking and service delivery between citizens and government is influenced and can be provoked by both citizens and government. In this chapter, the focus is explicitly on the interaction with citizens, who are either individually participating or in more or less organized groups (e.g. in associative forms). An explicit distinction between bottom-up and top-down pathways to collaboration is made. While there is a lot of literature on top-down, government initiated forms of collaboration, literature on bottom-up pathways is more diffused and fragmented, while it receives increasing attention (Brandsen, Trommel and Verschuere 2017; Edelenbos and van Meerkerk 2016a; Igalla, Edelenbos and van Meerkerk 2019). The aim of this chapter is to systematically reflect on these pathways: bringing together these different strands in the literature. It is argued that these pathways have their own dynamics and often reflect different objectives. Therefore, it is crucial to take notice of these different pathways as they give rise to different kind of implications and challenges for both governments and citizens in collaborative efforts in public policymaking and service delivery. Typical participation traps are pointed out for each of these pathways (cf. Howlett and Ramesh 2016).

At the same time it should be stressed that both pathways can be highly related: for instance, consulting citizens on policy proposals (as a form of top-down initiated collaboration) can provoke citizens to join efforts and to come up with their own initiative, challenging governmental-led policymaking. For analytical purposes it is useful though to make this distinction, to better capture different ways towards collaboration and their specific challenges, 
both from a governmental perspective as well as from the perspective of citizens. They give different meaning to the concept and practice of collaboration.

Top-down pathways of collaboration between governments and citizens can take different forms of which several are discussed by Kekez, Howlett and Ramesh in the introductory chapter to this volume, like consultation, citizen participation and co-production. Crucial here is the initiating role and dominance of governmental actors in involving citizens in policymaking or service delivery. While not necessarily the case, citizens are often involved at an individual level, especially in co-production when individual service beneficiaries are involved in individual transactions yielding mostly private value (Bovaird et al. 2015). Bottom-up pathways, in contrast, are characterized by citizens taking the lead in formulating and/or generating community goods and services. Crucial here is the self-organizing and initiating role of citizens (see section 3). These bottom-up initiatives have a group or collective nature and are (often) initiated by groups of citizens in the local community. Both forms can lead to more or less intensive ways of collaboration with government institutions. For instance, a bottom-up initiative of citizens to develop and manage community assets in urban regeneration can result in co-management (see Chindarkar, Chen and Wichelns, Chapter 6 in this volume) of these assets and of related public spaces (e.g. van Meerkerk, Boonstra and Edelenbos 2013). However they can also lead to forms of counter-production in which collaboration is hampered or in which interaction between governments and citizens is characterized by conflict or competing policy proposals (Edelenbos, van Meerkerk and Schenk 2018; Gofen 2015; Kleinhans 2017).

In the next section these two pathways are fleshed out, one by one. First, both forms will be more elaborated, taking notice of different drivers, forms and characteristics. Next, different issues and challenges in relation to both pathways will be discussed. Differences and similarities are explored between these pathways. The discussion is structured by going deeper into the why, how and who questions of bottom-up and top-down participatory efforts of governments and citizens, as these pathways are shaped by partly overlapping, but also differentiating motives (why?), crucial capacities (how?) and trigger different types of citizens (who?). Key participation traps in the pathways are distinguished. In the last section these two pathways will be compared and conclusions will be drawn, going deeper into the implications for future research.

\section{TOP-DOWN PATHWAYS TO COLLABORATION BETWEEN GOVERNMENTS AND CITIZENS}

There are different top-down pathways to collaboration between governments and citizens. Top-down pathways refer to arrangements which are organized 
by governments to include citizens directly in the formulation or implementation of public policy and public service delivery. Following the typology set out in the Kekez, Howlett and Ramesh's introduction, this include consulting and co-production arrangements (though co-production can also be an outcome of bottom-up pathways). Although the notion of collaborative arrangements might suggest some clear institutional design, in practice collaboration between governments and citizens is not necessarily experienced as such, comes about in different ways and forms and is driven by different motives. In this section, we go deeper into specific characteristics of top-down pathways to collaboration, driving forces and typical governance issues in managing these arrangements.

To dig deeper into top-down pathways to collaboration between governments and citizens we will build on different streams of literature. A first stream of literature in this respect concerns the vast amount of literature on citizen participation and related literature on stakeholder participation. Citizen participation is approached as a process in which individuals take part in decision making in the institutions and programs that affect them (Florin and Wandersman 1990). Efforts of governments to include citizens more directly in the formulation or implementation of public policy and service delivery can take various forms, including citizen panels, citizen juries, citizen charters, and participatory planning (e.g. Dryzek 2010b; Lowndes, Pratchett and Stoker 2001; Roberts 2004). Such government-led organized forms of participation has become a significant policy strategy in many Western countries. It has been put, for example, at the heart of spatial planning, environmental decision-making, social care, regeneration, housing and education policies (e.g. Irvin and Stansbury 2004; Marinetto 2003; Reed 2008; Roberts 2004).

A second stream of literature relevant for top-down pathways concerns the literature on co-production. Co-production of public goods and services comes in different shapes and sizes. Voorberg, Bekkers and Tummers (2015) have found that in general three different types can be distinguished: (1) citizen as co-implementer, (2) citizen as co-designer, and (3) citizen as initiator of public services. The first type is the most frequently found, whereas the third type is reported the least (and which is part of the bottom-up pathway). Some authors, like Bovaird et al. (2015: 3), define co-production broadly as 'making better use of each other's assets, resources and contributions to achieve better outcomes or improved efficiency'. This includes collective and community initiated forms of co-production (the third type) in which long-term relationships with professionalized service providers are developed (Bovaird 2007). Other co-production literature define co-production in a more narrow way. Based upon recurring elements in the literature, Brandsen and Honingh (2016) come with the following definition: 'Coproduction is a relationship between a paid employee of an organization and (groups of) individual citizens that 
requires a direct and active contribution from these citizens to the work of the organization' (Brandsen and Honingh 2016: 431). The last part indicates that much literature on coproduction mainly emphasizes the engagement from citizens to contribute to the work of already initiated and institutionalized forms and projects of public service delivery. Much literature on co-production therefore concerns top-down pathways of collaboration: the implementation of programs and projects are mostly induced and controlled by governments and other professionalized institutions.

A core characteristic of top-down pathways to collaboration is that governments decide when, who and how people get involved (Edelenbos, van Meerkerk and Schenk 2018). At certain moments in decision-making governments initiate participation procedures in which citizens get a chance to respond to or provide input for decision-making highly structured by rules set by the government. With regard to the how and who, typical issues emerge in top-down pathways. Before going deeper into these 'participation traps', it is first important to address why governments want to invest in such collaborative efforts.

\section{REFLECTING ON DIFFERENT TOP-DOWN PARTICIPATION TRAPS}

\section{Why}

Different motives for starting (top-down) citizen participation can be found in the literature. These motives are important to consider as they can explain strategies used as well as issues emerging in top-down pathways. For governments, key motives are increasing support for policies and governmental decisions, enhancing the quality of services and decisions made, breaking through deadlocks, avoiding litigation costs and building strategic alliances (Irvin and Stansbury 2007; Reed 2008; Roberts 2004).

While the idea of enhancing the quality of decisions is an important and frequently mentioned motive, the need for obtaining public acceptance is often a more powerful motive for governments to invest in participatory efforts. Irvin and Stansbury put it even stronger (2004: 57): 'Some citizen-participation programs primarily serve a marketing purpose, where the participation process consists of government representatives guiding citizens toward decisions the administrator would have made in the first place'. This is an important participation trap, as such participatory efforts easily run the risk of becoming symbolic forms of participation in which citizens don't have real influence. Inviting citizens to contribute to the formulations and implementation of public policy raise expectations about taking input and efforts seriously. Participating citizens expect that their input (values, interest, worries, etc.) 
are taken seriously into account. When these expectations are not met this can negatively impact on trust in government (Edelenbos and van Meerkerk 2016b; Irvin and Stansbury 2004). Some evaluative studies on relatively new participatory efforts (such as mini-publics and citizen juries) show that the impact of citizen input on policy- and decision-making is often not clear, but rather diffusive (Font and Blanco 2007; Jacquet 2017). We come back to this in the how question.

For citizens, important motives to collaborate in participatory efforts are also diverse, which are likely to vary given the specific form and context of engagement (e.g. advisory council, citizen jury, community planning), although empirical research in comparing such motivations is scarce. In general, an important motivation for citizens to engage is the opportunity offered to influence service design, delivery and/or other types of decision-making outcomes. Specifically, the stakeholder literature on participation stresses the influence on policy and implementation decisions as an important motivation (see Reed 2008). Also more altruistic motives are mentioned in the literature, such as contributing to the common good (Van Eijk and Steen 2016).

Important reasons for non-participation are negative perceptions about self-efficacy and capacities (e.g. perceived lack of political competence and expertise regarding the specific issue), but also negative perceptions about the meaning and impact of participatory efforts (Jacquet 2017; Lowndes, Pratchett and Stoker 2006). This underlines the importance of making clear and transparent what the aim of co-production or other participatory efforts are and how input is processed. Furthermore, it stresses the need for providing good information and support, making participation convenient and participants better able to participate. Both aspects relate strongly to the 'how' question of top-down participatory efforts.

\section{How}

Recurrent issues with regard to the management of participatory efforts are related with how citizens are involved. Important here is to consider the extent in which citizens get room for participation and collaboration and how this is organized. The famous ladder of Arnstein (1969) is often used to label the extent of participation, ranging from manipulation (as symbolic participation) to one-way consultation (as a form of tokenism) towards two-way collaboration and citizen control (at the other side of the spectrum). Authorities often lack experience and abilities with participatory efforts and/or fear losing power, leading to government-citizen collaboration often remained limited to providing information or consultation (Leach and Pelkey 2001; Tatenhove, Edelenbos and Klok 2010; Videira et al. 2006). In this respect, top-down pathways generally include the lower parts of Arnstein's rung, ranging from 
manipulation to forms of one-way consultation, while partnerships, delegated power and citizen control (the top rungs of Arnstein's ladder) are much harder to achieve in practice (Reed 2008).

While the ladder of Arnstein is static and disregards the complexities of collaborative and interactive governance processes it points at the issue of whether citizens are truly empowered in top-down participation by which meaningful interaction can emerge (see also Johnson and Howsam, Chapter 3 in this volume). Various literature on citizen participation stresses the importance of matching expectations of participatory efforts and the methods and strategies used to put participation into practice (Tritter and McCallum 2006). Other literature goes a step further and stresses the point that participants need to be empowered before meaningful participation can occur at all. This empowerment takes two forms (Reed 2008): (1) ensuring that participants have the power to really influence the decision and (2) ensuring that participants have the capability to engage effectively with the decision.

While not having the room to be exhaustive, several key factors and traps in fulfilling expectations can be mentioned. Key factors in empowering participants are how governments organize participatory processes and how responsive they are to citizens' input. Research shows that especially this response is one of the biggest deterrents (Lowndes, Pratchett and Stoker 2006). A lack of institutional linkages between existing power structures and participatory spaces is often pinpointed as a crucial barrier here (Edelenbos 2005; Healey 2006). Participatory forums often run parallel to formal decision-making processes hampering real meaning and impact. Political and managerial competences (see introductory chapter) are particularly needed to prevent this participation trap. In particular, the organizational capabilities, like creating communicative and procedural linkages between formal decision-making structures (e.g. within the local Council, within administrative project and expert groups) and participatory spaces. A crucial task for managers organizing participation efforts is to make participation transparent and to ensure feedback mechanisms about how input is processed.

For the more 'ambitious' participatory efforts aimed at two-way communication and deliberation between governments and citizens, the idea of developing an authentic dialogue and due deliberation is stressed by scholars often building on deliberative democracy theory (Dryzek 2010b; van Meerkerk, Edelenbos and Klijn 2015). This includes the idea that problem definitions and goals of participation are deliberatively discussed with participants. This requires important managerial competences, like skilful facilitation of informal group discussions, including maintenance of ' $\ldots$ positive group dynamics, handling dominating or offensive individuals, encourage participants to question assumptions and re-evaluate entrenched positions' (Reed 2008: 2425). 
According to the review of Reed (2008) among stakeholder participation literature in environmental governance, citizens typically get involved in decision-making at the implementation phase of the project cycle, and not in earlier project identification and preparation phases. Engagement with stakeholders as early as possible in decision-making has been frequently cited as essential if participatory processes are to lead to high quality and more meaningful decisions (Reed 2008). Typically, stakeholders only get involved in decision-making at the implementation phase of the project cycle, and not in earlier project identification and preparation phases, hampering meaningful influence. This may make it a challenge to motivate participants. Furthermore, it places participants in a reactive position, where they are asked to respond to proposals that they perceive to have been finalized already (Chess and Purcell 1999).

Next to ensuring influence and facilitating participatory processes, participants must also be able to participate. The capabilities of participants is an often mentioned factor in the participation literature (e.g. Lowndes, Pratchett and Stoker 2006; Reed 2008; Verba, Schlozman and Brady 1995). Governments can invest in developing the knowledge needed to create a more equal level playing field during participation trajectories. Furthermore, they can invest in capacity building aimed at ensuring that citizens are given the support to develop the skills and resources needed to engage (Lowndes, Pratchett and Stoker 2006).

Another view on the 'how' question is to make different participation options for different target groups. This can also provide a better matching of expectations in terms of motivation for participation (the motive of participants), its form and the costs of participation. As Lowndes, Pratchett and Stoker (2006: 288) put it:

The variety of participation options for engagement is important because some people are more comfortable with some forms of engagement such as a public meeting, while others would prefer, for example, to engage through on-line discussions. Some people want to talk about the experiences of their community or neighbourhood, while others want to engage based on their knowledge of a particular service as a user.

A related issue to empowerment concerns scale: the 'appropriate level' of participation (Roberts 2004). As organizing meaningful two-way forms of communication between public officials and citizens by which authentic dialogue and deliberation can occur, group size becomes an important parameter in the participation equation. It is clear that for due deliberation groups should not be too large. Group-level participation involves citizens in groups ranging in size from 3 to 75 (Roberts 2004: 332). Due deliberation requires thoughtful examination of issues and communicative processes of opinion and 
will-formation are of central concern rather than aggregation of interests and opinions (Dryzek 2010b). Due deliberation is grounded in an assumption that preferences of individuals are not fixed, but can change in debate and political dialogue (Held 2006).

It requires information about an issue, knowledge of the basic elements of a problem, as well as an understanding of the relationships among the elements and the consequences and tradeoffs associated with different policies. The larger the number of people involved in direct participation, the harder it is for public judgment to emerge. (Roberts 2004: 332)

The how question also points at the dynamics in participatory efforts. Next to the motivations, competences and capacities of both governments and citizens this refers to the quality of the interaction process. Various literature on participation and co-production stress the need for developing trustful relationships between government officials and participants and among different groups of stakeholders or participants. In the Kekez, Howlett and Ramesh introduction this is also discussed, referring to the managerial and political competences at the organizational level. Trustful relationships enhance the quality of information exchange and mutual learning, contributing to both the satisfaction of the participatory process as perceptions about the quality of the outcomes (Irvin and Stansbury 2004; van Meerkerk and Edelenbos 2014). Summarizing one of the main findings of a comparative case study analysis on the role of process design of participatory processes on sustainable land management De Vente et al. 2016: 5 note: 'If information exchange occurred through face-to-face contact between participants, there was also a significantly greater likelihood that the process would lead to sustainable solutions; conflict resolution; increased trust among nonstate actors and between nonstate actors and researchers'.

\section{Who}

Which groups of citizens are and should be involved remains a highly debated issue in the participation literature. Many experiences in collaborative efforts with citizens show that the 'usual suspects', the highly educated, resourceful and political active citizens, are overrepresented as compared to members from lower socio-economic groups (e.g. Irvin and Stansbury 2004; Koehler and Koontz 2008).

To avoid the issue of 'usual suspects' lots are increasingly used as a way to recruit participants. For instance, lots are part of the design of mini-publics. Mini-publics are participatory forums gathered for deliberation on a specific topic lasting one or more days. Various forms and designs exist, but the most 
standardized are citizens' juries, deliberative polls and citizens' assemblies (Grönlund, Bächtiger and Setälä 2014; Jacquet 2017). One of the most important reasons to use lots is to increase inclusiveness and representation as random selection ensures that each person in the sampled population has an equal chance of being selected. However, experience shows that due to self-selection mechanisms still the better educated and politically active (and more politically interested) citizens participate (Goidel et al. 2008; Michels 2017).

Furthermore, critical concerns are often raised with regard to the capture of participatory spaces by specific interest groups (Irvin and Stansbury 2004). In this respect, another perspective on the 'who' question is to ensure that relevant stakeholders and groups holding different views need to be approached and included. This requires analytical competences in particular. For instance, careful ex ante stakeholder analysis is an often mentioned method for identifying stakeholders, categorizing and differentiating between stakeholders (preferable with stakeholders) and - as a more advanced form - investigating relationships between stakeholders (Reed 2008).

Thus, recurring issues with top-down pathways to collaboration is that expectations of influence are raised, but not met in practice. Moreover, continuous motivation and commitment of governments and citizens is challenging in top-down pathways. Citizens are often not satisfied with the strictly conditioned rules of engagement, particularly when their degree of influence in decision making turns out to be low (Irvin and Stansbury 2004; Lowndes, Pratchett and Stoker 2001). Furthermore, critical concerns are raised about the usual suspects participating in these top-down constellations. As an alternative to top-down pathways, bottom-up pathways emerge in which citizens themselves set the rules for their engagement. This may lead to government participation. In the following section we go deeper into this pathway to (potential) collaboration between citizens and governments.

\section{BOTTOM-UP PATHWAYS TO COLLABORATION BETWEEN GOVERNMENTS AND CITIZENS}

Collaboration between governments and citizens can be provoked bottom-up, by citizens themselves. Denters (2016) refers to created spaces of participation by citizens versus invited spaces of participation referring to government-led forms of participation. In this respect, there seems to be a growing trend of community-based initiatives in which citizens organize themselves to deliver public services for their community, such as the maintenance of public spaces, running a community facility, setting up a cooperative or charity to provide community-led care services for the elderly in the area or environmental initiatives aiming to provide local renewable energy (Brandsen, Trommel 
and Verschuere 2017; Edelenbos and van Meerkerk 2016a; Healey 2015). These community-based initiatives are increasingly considered to be valuable agents in the creation of public value by policymakers, since governments have implemented austerity measures and cuts in policy programs, alongside longer trends of welfare retrenchment (Kleinhans 2017). Moreover, various campaigns and policy initiatives in Western countries have increasingly been aimed at shifting responsibilities and engaging civil society in the production of public services (e.g. Brandsen, Trommel and Verschuere 2017).

In this chapter we use the concept of community-based initiatives (CBIs) to refer to these bottom-up citizen activities in which citizens mobilize capacities and resources to collectively define and carry out actions aimed at providing public goods or services for their community; citizens control the aims, means, and actual implementation of their activities (Healey 2015). A systematic literature review by Igalla, Edelenbos and van Meerkerk (2019) reveals the main features that characterize community-based initiatives:

1. They are often locally oriented, which means that:

i. local residents, often collectives of residents, are the initial driving force behind the initiatives;

ii. they mobilize volunteers from within the community; and

iii. they focus on community needs;

2. They provide and maintain an alternative form of traditional governmental public services, facilities, and/or goods themselves;

3. They strive for autonomy, ownership, and control regarding decision making;

4. They are often linked to formal institutions, such as local authority, governmental agencies, and NGOs, especially for facilitation and public funding;

5. They often use market-based approaches to increase financial stability, but not aim at profitmaking.

For a number of reasons interdependent relationships between government organizations and community-based initiatives exist. For instance, community-based initiatives need resources (subsidies, knowledge, etc.) and legitimacy from governments to make their initiative viable or simple to execute their plans (Healey 2015; Korosec and Berman 2006). Government support or allowance, especially in dense regulated policy areas, is often important for community-based initiatives to grow or succeed (van Meerkerk, Kleinhans and Molenveld 2018).

However, these initiatives arise from different motives and collaboration with governments is not self-evident. Just like top-down pathways to government-citizen collaboration, bottom-up pathways come along with their own participation traps. 


\section{BOTTOM-UP PARTICIPATION TRAPS}

\section{Why}

CBIs can arise from dissatisfaction or complaints about governmental policy and actions or emerge in spaces that governments withdraw from due to budget cuts (e.g. Edelenbos, van Meerkerk and Schenk 2018; Gofen 2015). For example, in the field of environmental planning, citizens may develop alternatives to government proposals. This can be an explicit reaction to government-led participatory efforts in which citizens do not feel sufficiently heard or in which they are, in their opinion, involved too late in the decision-making process. As a response and to avoid being marginalized as exclusively negative and driven by NIMBYism (Not In My Back-Yard), they can be triggered to develop their own initiative (Edelenbos, van Meerkerk and Schenk 2018).

Similar motivations are found in the literature on citizen-initiated co-production. For example, Van Eijk and Steen (2016) found that dissatisfaction was an important motivation for citizens participating in neighbourhood watches. This type of motivation is also referred to as the salience of the issue at stake. They note that dissatisfaction about the current situation - perceptions about an unsafe environment and beliefs about the inability of the police to respond in time - was an important drive for citizens to start a neighbourhood watch. In contrast with the top-down forms of co-production they studied (e.g. client councils in health care organizations), dissatisfaction was a more salient motivation in this bottom-up form of co-production.

Community-based initiatives also emerge in spaces that governments withdraw from due to budget cuts, and in domains that 'slipped' governmental attention. For example, in the field of Dutch health care cooperative emerge which are partly a response to the downsizing and upscaling of health care organizations, especially in rural areas. Also, in the field of urban regeneration, both in the UK (for quite some time now) and the Netherlands (more recently), community enterprises have emerged which are partly a response to government retrenchment and budget cuts in this field (Bailey 2012; Kleinhans 2017; van Meerkerk, Kleinhans and Molenveld 2018). Coming back to the example of the neighbourhood watch studied by Van Eijk and Steen (2016), austerity measures were also an important cause for citizens to start their own initiative. As they note, reporting on their focus group findings (Van Eijk and Steen 2016: 39): 'Because of austerity in public finances, the police and citizens must work together'. 'Pressure on government is increasing and then you want to take on your responsibility' and 'you have own responsibilities as well for the safety in your own environment'. 
Another type of motivation is perceptions about the effectiveness of participation. This is referred to as external efficacy (Van Eijk and Steen 2016; Alford 2002). For instance, in the field of urban regeneration, CBIs emerge motivated by the idea to realize a more integrative and continuous approach to community issues as a response to more mono-centric, project-oriented government-led approaches. For instance, community enterprises (as a specific form of CBI) aim to integrate social, environmental and economic benefits in their approaches to neighbourhood development and fighting deprivation (Bailey 2012). An important motivator for such CBIs is the idea that they can make a difference by developing a more community-led, anchored and holistic approach.

Building on the large amount of literature on volunteers' motivations several other, more personal factors to engage in community-based initiatives can be mentioned, for instance perceived personal rewards such as developing competences and enhancing self-esteem (see Alford 2002; Van Eijk and Steen 2016). Moreover, opportunities for connecting to others in relation with enhancing social cohesion in the neighbourhood is also a particular motive for participants in CBIs. Various studies have shown that the link with the neighbourhood is important. Although these motivations are also mentioned in the literature on top-down participation, they are likely to be more strongly present in bottom-up participation (see next section).

Lastly, a more broad type of motive mentioned in the literature are so-called community-centred motivations (Alford 2002; Van Eijk and Steen 2016). In this respect, this can refer to beliefs about the importance of contributing to the public good. Comparable with public service motivation. The idea of realizing empowerment, citizen self-control or 'doing democracy' can be a powerful motivator for bottom-up forms of engagement.

Resuming the motivations of citizens to initiate CBIs, both collective outcomes as personal rewards play a role, as also pointed out in the broader literature on civic participation (Schlozman, Verba and Brady 1995). CBIs seem to be characterized by this balance in which there is both room for collective rewards and personal connections (Denters 2016). Crucial is that citizens have the idea that they can make a more direct difference for their living environment (Bang 1999).

Participation traps may lie in the perceived legitimacy of CBIs' motivations (cf. Edelenbos, van Meerkerk and Schenk 2018). CBIs might become a vehicle for those stakeholders with many more resources (information, money, time, skills, etc.) to exert influence on policymaking and service provision that serves their private interests under the label of community and joint interests (Taylor 2007). Furthermore, governance challenges in keeping CBIs running and keeping participants committed and motivated over time is another potential trap for CBI initiators. 
For governments, the existence and effectiveness of these initiatives can be essential and of strategic interest (Korosec and Berman 2006), making it worthwhile for governments to develop supportive relationships with community-based initiatives. First, community-based initiatives develop resources (people, activities, knowledge, implementation power, etc.) which may be useful for cost-effective service provision. For example, financial restraints and budget cutbacks may stimulate governments to seek and activate new forms of civic engagement, like social entrepreneurship and community self-organization, in order to maintain a certain level of service delivery in the fields of retreat (for example health care, sustainable energy, etc.) (Edelenbos and van Meerkerk 2016a). In this respect, some 'analysts may see [community-based] initiatives as an expression of a "neo-liberal" downsizing of the state, and to some extent they are filling gaps left by a retreating state' (Healey 2015: 117). Next, involvement of governments might be approached as normal given the significance of government in current society; its support is important and often crucial for community-based initiatives to succeed, especially in institutionally dense policy areas (Brandsen 2016). Moreover, community-based initiatives and social entrepreneurs bring experimentation and innovation, which is often problematic to achieve in bureaucratic organizations like governments (Korosec and Berman 2006).

An important dilemma for governments in whether to support CBIs in one form or the other is the question of how representative the initiative is for the local community (Denters 2016; Edelenbos, van Meerkerk and Schenk 2018). Furthermore, when CBIs are supported or are provided a greater role in the production of public services, the issue of formal accountability arises. In this respect, enhancing CBIs or giving them more influence on public issues (e.g. the maintenance of public spaces) can come at the price of government control. Next, collaboration with CBIs can be quite time-, resource-, and skill-consuming for governments; specifically as this often requires customization: tailor-made solutions for a specific project. This might conflict with key values such as the state's legality, reliability and impartiality (Grotenbreg and Altamirano 2017). Fourth, politicians and executives may consider community-based initiatives, which often rely on crucial efforts of volunteer behaviour, as unreliable, because of the unpredictable behaviour or commitments of citizens (Roberts 2004). In this respect, a 'risk-averse, conservative administrative culture' may explain why citizens are not considered as a reliable resource providing partners (Voorberg, Bekkers and Tummers 2015). Community-based initiatives are often engaged in new ways of delivering services, which had hitherto been regarded as strictly professional, thereby changing the rules of the game or deviating from established policy and practices (Gofen 2015). Next, political and professional reluctance to lose status 
and control can also explain the unwillingness to support community-based initiatives (Kleinhans 2017; Voorberg, Bekkers and Tummers 2015).

\section{How}

Resources and mobilization capacities are key factors to consider in determining how CBIs develop and which participation traps can be distinguished (Denters 2016; Verba, Schlozman and Brady 1995). Key resources for CBIs to emerge and sustain are different forms of social capital (bonding, bridging and linking capital), entrepreneurial community leadership and government support (Igalla, Edelenbos and van Meerkerk, 2019; van Meerkerk, Kleinhans and Molenveld 2018).

Social capital facilitates the mobilization of resources (e.g. knowledge, information and experience), co-ordination of actions, and creation of safety nets that reduce risks for individual community members (Peredo and Chrisman 2006). CBIs 'can harness social capital in local communities and use it to achieve positive outcomes through mobilizing volunteers, board members and paid staff' (Bailey 2012: 30). The literature on social capital generally distinguishes three types: bonding, bridging and linking social capital (Putnam 2000; Woolcock 2001). In the context of CBIs, bonding social capital is derived from strong ties between neighbours, friends and association members. These ties help to explain the formation of CBIs and dynamics in board management and continuity (Bailey 2012; Somerville and McElwee 2011). Bridging capital refers to the ties of the CBIs in the wider neighbourhood, ties to other networks and other community organizations. Bridging capital can generate support and a base for recruiting volunteers, thereby potentially enhancing the organizational capacity and legitimacy of CBIs (Bailey 2012; Healey 2015; Kleinhans 2017; Somerville and McElwee 2011). Linking capital refers to ties that CEs have with institutional key players, which can be crucial for getting resources and support.

Another crucial and typical factor for CBIs and bottom-up pathways to collaboration is community leadership. This plays an important role in the mobilization of resources and development of organizational capacities. Community leadership includes mostly managerial and political competences as community-building and mobilizing capacities, skills to build collaborative and strategic alliances and skills for identifying and exploiting new entrepreneurial opportunities (e.g. Purdue 2001; Selsky and Smith 1994).

From a critical stance, CBIs might give shape to new divides between those citizens who are capable to organize themselves and those who are not. Both community leadership skills and social capital, key factors in the development and durability of CBIs (van Meerkerk, Kleinhans and Molenveld 2018), is unequally dispersed among neighbourhoods. Furthermore, just 
because self-organizing citizen groups are connected around a particular kind of identity, they can be exclusive. Moreover, in order to function effectively, homogeneity and exclusion can be helpful, if not necessary in the context of self-organization (Dietz, Ostrom and Stern 2003). That is, developing commitment and trust is far more easy in smaller, more defined groups where participants can interact in a face-to-face mode (McLennan 2018; Pestoff 2014). Hence, from a democratic point of view, keeping CBIs inclusive and open to different groups of citizens is a challenge.

Entrepreneurial oriented forms of CBIs, such as community enterprises, strive for considerable autonomy and own income sources and are characterized by hybridity: referring to the dual mission of realizing financial sustainability and a social purpose (e.g. Bailey 2012; Doherty, Haugh and Lyon 2014). Generating own income (through a business model) and simultaneously adding social value, are crucial for those types of CBIs. This hybridity may cause difficult trade-offs. On the one hand, financial considerations may 'squeeze out' social goals, which is also a risk for the legitimacy of CBIs. On the other hand, mainly emphasizing social goals endangers the financial aspects of the business and thus threaten its survival. Various studies suggest that entrepreneurial forms of CBIs face considerable governance challenges to keep their organization running and effective over time, that is, delivering particular services and social benefits to the target community (e.g. Bailey 2012; van Meerkerk, Kleinhans and Molenveld 2018). Key governance challenges are management, in particular recruiting board members with the right skills and experience, involving local people and other partners through participatory decision-making processes, and balancing the dual mission of social benefits and financial sustainability (van Meerkerk, Kleinhans and Molenveld). Achieving sufficient staff capacity is a recurring challenge for CEs, which commonly depend on volunteers and a few (if any) paid staff members.

Government support or facilitation may come in different forms. Some authors roughly indicate that the supportive action of governments is important for the potential future of community-based initiatives as this can boost their start and growth in scale and scope (Healey 2015). This can be in general moral or material support, for example by providing grants, technical and managerial expertise, and advisory services in order to improve the management and operational capacity of CBIs. Next to material support, several scholars stress that community-based initiatives benefit from guidance through bureaucratic tangles and by enabling legal and policy environments (Healey 2015; van Meerkerk, Boonstra and Edelenbos 2013).

Korosec and Berman (2006) distinguish several ways in which public officials and civil servants can support leaders and members of community-based initiatives (they focus on social entrepreneurship in particular). They distin- 
guish different types of government support, covering in particular political and managerial competences:

- Raising awareness. This can enhance legitimacy and interest to the efforts of community-based initiatives. Moreover, governments can collect and provide data on important social issues and educate beginning civic entrepreneurs in planning, programming and resource-development strategies (grant writing or facilities planning);

- Providing assistance in acquiring resources. Government officials can join community-based initiatives in submitting grants and funding proposals and pledge to match funds from private sources. Next, governments can also directly support community-based initiatives by providing in cash (money) or in kind (time, attention) resources, regardless of proposals to other funding sources. Government can also get leaders of community-based initiatives in contact with organizations and community groups with space and leasing opportunities.

- Assistance in co-ordination and implementation. Governmental organizations can initiate and facilitate interaction and cooperation between members of community-based initiatives and other private, non-profit, community and public organizations. They can also play a key role in fostering connections and collaborations between projects and creating portfolios of inter-connected initiatives. Furthermore, public managers ' ... can also help ... by assisting in matters that make program implementation easier, such as expediting permitting or approval for a project' (Korosec and Berman 2006: 450).

Although governments may consider community-based initiatives interesting, for example, for enhancing service delivery, or even stimulate their development, the willingness and capability of governments to actually provide support is not that straightforward (Healey 2015). According to the literature on co-production of public services (including citizen initiated forms of co-production), government organizations are often not compatible with such initiatives. They often lack the presence of inviting organizational structures and procedures within the public organization and infrastructures to communicate with citizens or to collaborate with community-based initiatives (Kleinhans 2017; Voorberg, Bekkers and Tummers 2015). Furthermore, public servants might find it too much of work, which intervenes with their daily business or they may simply lack incentives to invest in collaboration with community-based initiatives. As Voorberg, Bekkers and Tummers (2015: 1342) note: for public officials, 'it is often unclear to what extent public services can be improved by incorporating citizens or how co-creation creates budgetary benefits'. Third, government support and interventions may come 
at the price of turning CBIs into something quite different (Brandsen 2016). Forcing them to comply with regulations, pushing them towards formalization and professionalization in order to receive financial support may crowd out motivation and enthusiasm among CBIs' participants.

\section{Who}

The question of how representative the organization is for the wider community poses challenges in requiring resources (e.g. community assets, funding) or acceptance from public bodies (Edelenbos, van Meerkerk and Schenk 2018). Although the body of evidence on the representativeness of CBIs participants and initiators is not that big, several Dutch studies show that CBI are able to attract a diverse pool of participants (Bakker, Denters and Klok 2011; Igalla and van Meerkerk 2015). In comparison with top-down forms of participation they do not have a strong bias for the usual suspects, although it is important to make distinctions between different roles here. The various literature on CBIs stresses the role of community leaders with mobilizing, inspiring and boundary spanning qualities (Purdue 2001; van Meerkerk, Kleinhans and Molenveld 2018). These initiators and 'managers' of CBIs generally are higher educated and often have previous experience in public sector jobs (Denters et al. 2013; Igalla and van Meerkerk 2015). Other types of participants, for instance working as volunteers for specific projects or activities, have far more diverse backgrounds. Furthermore, from their study on Dutch CBIs Bakker, Denters and Klok (2011) came to the conclusion that despite biases in descriptive representation, views of participants and non-participants on the problems in their neighbourhood were strikingly similar.

\section{DISCUSSING KEY PARTICIPATION TRAPS AND CRUCIAL COMPETENCES IN TOP-DOWN AND BOTTOM-UP PATHWAYS}

This chapter has reviewed bottom-up and top-down pathways to governmentcitizen collaboration with a particular focus on citizen participation. Various participation traps in relation to the why, how and who question. In this section the two pathways will be compared.

Wrapping up the motivations for participating in top-down or bottom-up pathways (the why question), we can conclude that bottom-up pathways can partly be seen as a response or alternative to the participation traps in top-down pathways. In the top-down pathway a frequently sited participation trap concerns the mismatch of expectations of participants and their level of influence on decision-making and implementation. A lack of feedback mechanisms between formal decision-making and participation processes or 
imbalance in motivation (more oriented towards gaining support for already made decisions) could endanger top-down participation, turning into symbolic participation. Moreover, low levels of perceived efficacy among citizens can easily diminish broad or committed participation.

In this respect, bottom-up forms of participation seem to be partly a response to these issues of top-down participation. Perceived levels of external efficacy (having real influence, 'seeing' direct results), dissatisfaction with government-led participation or with perceived levels and quality of service provision are strong motivators for citizens to start their own initiative. However, more research is needed into the (long-term) motivations of participants in CBIs and to compare these types and levels of motivation with top-down forms of participation (e.g. government-initiated co-production, consultation). Moreover, an intriguing question for future research is when and how citizens get triggered to start their initiative, in particular as governments in several Western welfare states have adopted measures to stimulate 'active citizenship' (Brandsen, Trommel and Verschuere 2017; Verhoeven and Tonkens 2013). Though the literature on co-production has developed quite some knowledge on different types of motivations (e.g. Alford 2002; Van Eijk and Steen 2016), less attention has been paid to how external interventions impact on the intrinsic motivation of citizens to start collective forms of co-production and to keep their initiative running. This would mean more research on the effects of, for instance, government strategies and government responsiveness on citizens' intrinsic motivation. Psychological theories, such as Self-Determination Theory and Motivation Crowding Theory, offer promising frameworks to go deeper into different psychological components of intrinsic motivation and how external interventions may impact upon these.

Concerning the 'how' question, various competences were pointed out in line with those discussed in the introductory chapter to the volume. In particular, the managerial and political types of competences are key for both pathways, though they have a somewhat different shape. In top-down pathways political and managerial competences to effectively link participatory spaces with formal power structures seem crucial to overcome the participation trap of loosely coupled participatory processes (consultation or more deliberative forums) lacking responsiveness. However, the issue of responsiveness seems to be even more salient for bottom-up pathways to collaboration as they are more challenging for existing roles and structures vested in governmental institutions (Edelenbos, van Meerkerk and Koppenjan 2017; cf. Torfing et al. 2012). In this respect, various literature point out that facilitative organizational structures, autonomy of public managers and their boundary spanning capabilities are particular important for building collaborative and innovative governance arrangements with community-based initiatives (McLennan 2018; van Meerkerk and Edelenbos 2018). 
Furthermore, the individual and organizational capabilities addressed in the introductory chapter are not only governments' capabilities, but in bottom-up pathways they are particularly also about citizens' capabilities. Managerial and political competences of initiators and leaders of CBIs, such as their mobilizing capacities, entrepreneurial skills and abilities to build strategic alliances are highly important for their performance and durability, as well as impacting on the relationship with governments (Igalla, Edelenbos and van Meerkerk 2019; van Meerkerk, Kleinhans and Molenveld 2018).

An important question for future research in this respect is under which conditions governments and citizens in bottom-up pathways complement each other (cf. McLennan 2018). Citizens can add or bring in different resources, competences and capabilities (e.g. local knowledge, networks, local commitment, creativity and community leadership skills). In the search for enhancing governance capacity, a recommendation for governments would be to carefully scan for, trigger and mobilize existing initiatives and to look for ways to complement these. Moreover, governments can play an important role in on the one hand safeguarding certain democratic values, while at the same time providing external authority which enhances the impact of CBIs.

Concerning the who question, a clear critique on top-down participation is the mobilization of usual suspects. For bottom-up participation, there are indications that more diverse groups of citizens participate, though initiators and also the more large or professional CBIs are often run by 'usual suspects'. However, this is not that clear yet and provides another avenue for future research to find out. 